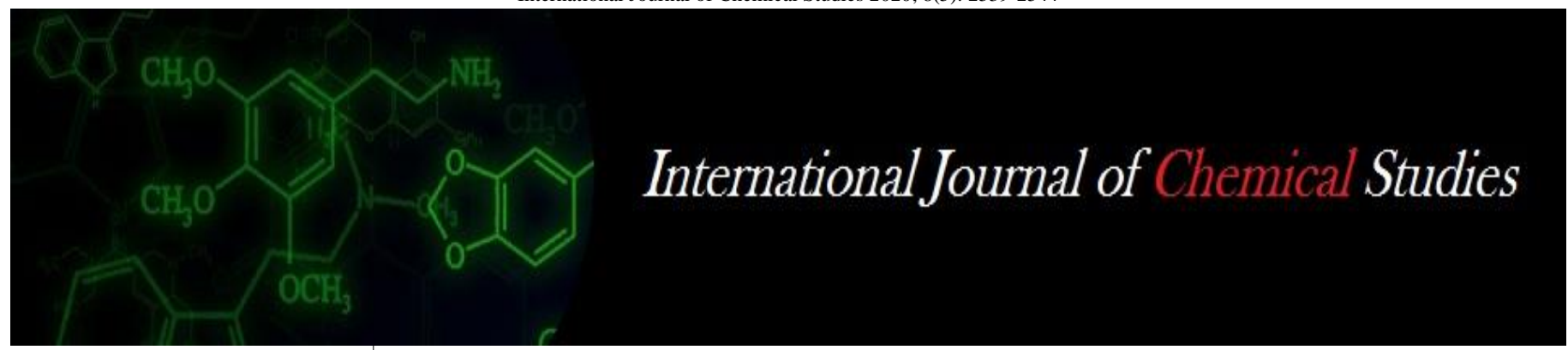

P-ISSN: 2349-8528

E-ISSN: 2321-4902

www.chemijournal.com

IJCS 2020; 8(5): 2539-2544

(C) 2020 IJCS

Received: 25-06-2020

Accepted: 29-07-2020

\section{Karmjeet Kaur}

Department of Food and

Nutrition, Punjab Agricultural

University, Ludhiana, Punjab,

India

\section{Dr. Harpreet Kaur}

Department of Food and

Nutrition, Punjab Agricultural

University, Ludhiana, Punjab,

India

\section{Dr. Kiran Bains}

Department of Food and

Nutrition, Punjab Agricultural

University, Ludhiana, Punjab,

India

Dr. Jaswinder K Brar

Department of Food and

Nutrition, Punjab Agricultural

University, Ludhiana, Punjab,

India

\section{Dr. Preety Ahluwalia}

Department of Food Science and Technology, Punjab Agricultural University, Ludhiana, Punjab,

India

\section{Dr Amarjeet Kaur}

Krishi Vigyan Kendra, Faridkot

Punjab Agricultural University,

Ludhiana, Punjab, India
Corresponding Author: Karmjeet Kaur

Department of Food and Nutrition, Punjab Agricultural University, Ludhiana, Punjab, India

\section{Glycemic response of chapati (Indian flat bread) developed from cereal pulse blends}

\author{
Karmjeet Kaur, Dr. Harpreet Kaur, Dr. Kiran Bains, Dr. Jaswinder Kaur \\ Brar, Dr. Preety Ahluwalia and Dr. Amarjeet Kaur
}

DOI: $\underline{\text { https://doi.org/10.22271/chemi.2020.v8.i5ai.10700 }}$

\begin{abstract}
The study was conducted to develop culturally acceptable low glycemic chapati (Indian flat bread) for diabetic patients. The acceptability, nutritional composition and glycemic index (GI) of the developed chapati were assessed. Oat, barley, soybean and chickpea flour were incorporated into the whole wheat flour, by using ten different flour combinations. The developed chapati was compared with corresponding control chapatti. The overall acceptability of chapati prepared form the blend of whole wheat flour with soybean (75 and 25\%) and with whole wheat flour, barley and soybean in the proportion of 50, 25 and $25 \%$ was significantly $(p<0.05)$ higher as compared to control (whole wheat flour). The results of proximate analysis revealed a significantly $(p \leq 0.05)$ higher fibre, protein and a significantly $(p \leq 0.05)$ lower carbohydrate content in the developed chapati. The Glycemic Index of chapati prepared from whole wheat flour, barley and soy flour $(50,25$ and $25 \%)$, had significantly $(p \leq 0.05)$ lower GI(52). Increased protein and crude fiber content and decreased carbohydrates resulted in a significant $(p \leq 0.05)$ reduction in the GI of chapati. It came in the category of low glycemic foods $(<55)$ as per WHO classification of low GI foods, hence it can be included in the regular diets of the diabetic patients to prevent further complications.
\end{abstract}

Keywords: Oat flour, barley flour, soy flour, chickpea flour, chapati, blood glucose, glycemic index

\section{Introduction}

Diabetes mellitus has become an important public health challenge. It is the main cause of death and disability throughout the world. Global prevalence of diabetes has doubled between 1980 and 2014 (IDF,2013) ${ }^{[8]}$. According to the International Diabetes Federation, one in 11 adults had diabetes during 2015 and the number is expected to be one in 10 in 2040 (IDF, 2015) ${ }^{[7]}$. India is the member country one of the International Diabetes Federation SEA (South East Asia) region. International Diabetes Federation, 2017 has shown that globally 425 million people have diabetes and in the SEA region 82 million people have the disease; it could go up to 151 million by 2045 . India is at the $2^{\text {nd }}$ position after China with 72.9 million cases of Type 2 diabetes in the age group of 20-79 years and there are estimates that India will be at first position with 134.3 million cases of Type 2 diabetes by 2045 (IDF,2017) ${ }^{[9]}$.

Intake of refined carbohydrates has been increased over the years and it has shown the upward trend in the prevalence of obesity and type 2 diabetes in the US, indicating that the type of carbohydrate consumed may impact disease risk through alterations in postprandial blood glucose and insulin concentrations (Augustin et al. 2002 and Gross et al. 2004) ${ }^{[3,5]}$.

To account for these qualitative differences in carbohydrate type, the concept of glycemic index (GI) was developed by Jenkins et al. (2008) ${ }^{[10]}$ as a physiologic rather than a structural approach for classifying carbohydrates. Glycemic index (GI) describes the blood glucose response after consumption of a carbohydrate containing test food relative to a carbohydrate containing reference food, typically glucose or white bread. GI was originally designed for people with diabetes as a guide to food selection, advice being given to select foods with a low GI. The amount of food consumed is a major determinant of postprandial hyperglycemia, and the concept of glycemic load (GL) takes account of the GI of a food and the amount eaten (Venn and Green 2007) ${ }^{[14]}$. The physiologic effect of a carbohydrate refers to the rate and magnitude in which dietary glucose enters the bloodstream after a meal, as well as the subsequent demand placed on the pancreas to secrete sufficient amounts of insulin to 
normalize blood glucose levels. Thus, postprandial plasma glucose and insulin concentrations following consumption of carbohydrate is highly governed by the quality and quantity of carbohydrate consumed (Augustin et al. 2002 and Aston 2006) $[3,2]$. A positive association was found between increased dietary GI and risk for coronary heart disease (Liu et al. 2000) ${ }^{[11]}$, whereas lower dietary GI was associated with a reduced risk for the development of type 2 diabetes in men and women (Salmeron et al. 1997a and Salmeron et al. 1997b) ${ }^{[12,13]}$. While several interventional studies have also reported beneficial effects of consuming low-GI diets.

For this reason, there is interest in using these concepts for diet prescription so large interest has recently risen in the development of functional foods or products that can offer health benefist beyond the traditional nutrients. The present study was planned to develop low glycemic index chapati for diabetic patients.

\section{Material and Methods}

The present study was aimed to develop low Glycemic Index chapati. The material and methods used have been discussed here.

\section{Procurement of food ingredients}

The basic ingredients, whole wheat flour, and functional food ingredients like oat flour, barley flour, soy flour and chickpea flour were collected at one lot from the local market and stored in bins and used for the entire study.

\section{Designing of blends}

Chapaties were prepared from the blends of different flours of cereals and legumes. Oats, barley, soybean and chickpea flour have been reported to have low glycemic index (GI). Ten different blends were prepared by using the above grain flours in different proportions by incorporating in whole wheat flour. The proportions of different ingredients in each blend to be used to prepare chapati is given in Table 1

Table 1: Combinations for chapatti

\begin{tabular}{|c|c|c|c|}
\hline & $\begin{array}{l}\text { Whole Wheat } \\
\text { flour (g/100g) }\end{array}$ & Oat flour $(\mathrm{g} / 100 \mathrm{~g})$ & Soy flour $(g / 100 g)$ \\
\hline Control & 100 & - & - \\
\hline Blend 1 & 25 & 50 & 25 \\
\hline Blend 2 & 50 & 25 & 25 \\
\hline Blend 3 & 75 & - & 25 \\
\hline \multicolumn{4}{|c|}{ Barley flour $(\mathrm{g} / \mathbf{1 0 0 g})$} \\
\hline Blend 4 & 25 & 50 & 25 \\
\hline Blend 5 & 50 & 25 & 25 \\
\hline & & Oat flour $(\mathrm{g} / 100 \mathrm{~g})$ & $\begin{array}{c}\text { Chickpea flour } \\
(\mathrm{g} / 100 \mathrm{~g})\end{array}$ \\
\hline Blend 6 & 25 & 50 & 25 \\
\hline Blend 7 & 50 & 25 & 25 \\
\hline Blend 8 & 75 & - & 25 \\
\hline \multicolumn{4}{|c|}{ Barley flour (g/100g) } \\
\hline Blend 9 & 25 & 50 & 25 \\
\hline Blend 10 & 50 & 25 & 25 \\
\hline
\end{tabular}

\section{Development of chapati}

Chapati was prepared using ten blends. The standardized recipes for control samples were prepared from whole wheat flour is given below. Blends were used to prepare test samples.

\section{Chapati}

\section{Ingredients}

Whole wheat flour:
Water: Optimal

\section{Method}

1. Knead the flour into dough by adding water.

2. The dough was divided into equal portions and each portion of the dough was rounded off between the palms of hands and rolled into a chapati with the help of rolling pin.

3. The chapaties were baked on thick iron sheet (tawa) heated by gas flame at constant temperature.

4. One side of the chapati took 45 seconds for getting baked then it was turned and other side was baked for almost the same time.

5. It was turned again and pressed with a clean cloth moving the chapati in the circular motion till it become fluffy like a ball.

\section{Organoleptic evaluation of chapati}

The developed chapatis were evaluated organoleptically by a panel of 15 subjects comprising of students and faculty of department of Food and Nutrition, PAU, Ludhiana. Each chapati sample was prepared and tested thrice. The samples were coded to avoid any bias. The panelists were asked to score the samples for color, appearance, flavor, texture, taste and overall acceptability by using a score card of 9 point Hedonic Rating Scale.

The highly acceptable chapati along with its corresponding control were weighed, homogenized and oven dried at $60^{\circ} \mathrm{C}$. Dried samples were stored in air tight plastic bags for proximate analysis.

\section{Nutritional analysis}

Moisture, total ash, crude protein, crude fibre, crude fat were assessed using standard methods.(AOAC 2000) ${ }^{[1]}$ The content of carbohydrates was calculated by subtracting the sum of moisture, protein, ash, fat and crude fibre from 100.

Carbohydrates $=100-($ Moisture + Protein + Fat + Ash + Fibre).

The energy content was calculated by factorial method.

Energy $($ Kcal $)=(4 \times$ protein $)+(9 \times$ fat $)+(4 \times$ carbohydrate $)$

Glycemic index of the developed products

Glycemic index of chapati was estimated, through a scientific approach of determining the glucose response in healthy subjects through meal tolerance test.

The experiment was conducted in the department of Food and Nutrition, College of Home Science PAU Ludhiana. All the subjects were informed beforehand about the experiment and their voluntary consents were taken before conducting the experiment.

\section{Selection of subjects}

For each product 10 volunteer healthy non diabetic subjects in the age group of 20 to $40 \mathrm{y}$ were selected. Assessment of glycemic response was done by taking finger prick capillary blood sample.

\section{Glucose tolerance test}

The subjects were asked to come for blood glucose test after overnight fast. On first occasion, $50 \mathrm{~g}$ carbohydrate in the form of glucose (reference) and on subsequent occasion test food (chapati) providing $50 \mathrm{~g}$ available carbohydrate was given to the subjects. Fasting blood glucose was checked. The volunteers were asked to consume test chapati within 10-12 minutes. The blood samples were drawn and checked after every half an hour interval for two hours for the post prandial 
level. The blood glucose response curves were plotted for both oral glucose tolerance test and test product.

The glycemic index was calculated using the formula given by Wolever and Jenkins (1986) ${ }^{[17]}$.

Glycemic index $=\frac{\text { Area under glucose curve after test meal }}{\text { Area under glucose curve after reference meal }} \times 100$

The Glycemic load (GL) was determined by the method of Salmeron et al. (1997). The GL was calculated based on the quantity of the recipe per serving and the respective available carbohydrate content. The following formula was used:

Glycemic load $=\frac{\text { Available carbohydrates }(\mathrm{g}) \times \mathrm{XI}}{\text {. }}$

100

\section{Statistical analysis}

The results of organoleptic scores, proximate analysis and glycemic index were statistically analyzed using analysis of variance technique and student's t test with the aid of Microsoft statistical analysis tool pack. The limit of probability fixed for the test of significance was $\mathrm{P}=0.05$. Wherever the significant results were obtained, the critical difference was calculated.

\section{Ethical issues}

Informed consent was obtained before conducting the experiment before feeding food items and checking the blood glucose of human subjects. The privacy rights of human subjects will always be observed.

\section{Results and Discussion}

The present study was conducted to evaluate the acceptability, nutritional composition and glycemic index of developed chapati s using different blends of whole wheat flour and legume flours.

\section{Organoleptic evaluation of developed chapati}

Chapaties were prepared using different blends (Table 1) and were evaluated organoleptically. The mean scores of colour,(Table 2) appearance, flavor, texture, taste and overall acceptability of 10 blends ranged from 7.33 to $8.06,7.00$ to $8.06,6.73$ to $7.87,6.81$ to $7.70,7.85$ to $6.67,6.54$ to 7.82 and maximum scores for colour and appearance (8.06) were observed with the blend of whole wheat flour, barley flour and soy flour in the proportion of 50, 25 and $25 \%$ followed by blend of whole wheat flour, barley flour and soy flour in the proportion of 25, 50 and 25 while for flavor, texture and taste maximum scores were observed in blend 3 containing whole wheat flour and soy flour (75 and 25\%). The minimum scores (7.33) for colour were observed in blend containing whole wheat flour, oat flour and soy flour (25, 50 and 25\%) and in blend 6 containing whole wheat flour, barley flour, chickpea flour in the proportion of 25,50 and $25 \%$.

The scores of overall acceptability were highest in control (8.03) followed by the blend containing whole wheat flour and soy flour in the proportion of 75 and $25 \%$ (7.82) and minimum in blend 6 (6.54). No significant difference was found in blend 3, 4 and 5 when compared with the control (Fig 1).

Table 2: Organoleptic scores of chapati using different blends

\begin{tabular}{|c|c|c|c|c|c|c|c|c|}
\hline & Flour combinations & $\begin{array}{c}\text { Amount } \\
(\mathbf{g} / \mathbf{1 0 0 g})\end{array}$ & Colour & Appearance & Flavor & Texture feel & Taste & $\begin{array}{c}\text { Overall } \\
\text { acceptability }\end{array}$ \\
\hline Blend 1 & Whole wheat flour+Oat+Soybean & $25+50+25$ & $7.33 \pm 0.83$ & $7.17 \pm 0.91$ & $6.73 \pm 1.18$ & $7.17 \pm 1.03$ & $6.89 \pm 0.95$ & $7.04 \pm 0.80$ \\
\hline Blend 2 & Whole wheat flour+Oat+Soybean & $50+25+25$ & $7.75 \pm 0.81$ & $7.58 \pm 1.08$ & $7.25 \pm 1.11$ & $7.44 \pm 1.00$ & $7.50 \pm 0.85$ & $7.53 \pm 0.77$ \\
\hline Blend 3 & Whole wheat flour+Soybean & $75+25$ & $7.89 \pm 0.62$ & $7.80 \pm 0.76$ & $7.87 \pm 0.63$ & $7.70 \pm 0.73$ & $7.85 \pm 0.64$ & $7.82 \pm 0.53$ \\
\hline Blend 4 & Whole wheat flour+Barley+Soybean & $25+50+25$ & $8.00 \pm 0.53$ & $7.97 \pm 0.45$ & $7.69 \pm 0.95$ & $7.67 \pm 0.79$ & $7.81 \pm 0.89$ & $7.80 \pm 0.65$ \\
\hline Blend 5 & Whole wheat flour+Barley+Soybean & $50+25+25$ & $8.06 \pm 0.53$ & $8.06 \pm 0.33$ & $7.69 \pm 0.89$ & $7.69 \pm 0.67$ & $7.75 \pm 0.77$ & $7.81 \pm 0.61$ \\
\hline Blend 6 & Whole wheat flour+Oat+Chickpea & $25+50+25$ & $7.33 \pm 1.12$ & $7.00 \pm 0.99$ & $6.81 \pm 0.12$ & $6.81 \pm 0.14$ & $6.67 \pm 1.07$ & $6.54 \pm 0.90$ \\
\hline Blend 7 & Whole wheat flour+Oat+Chickpea & $50+25+25$ & $7.44 \pm 0.88$ & $7.22 \pm 0.90$ & $7.28 \pm 0.88$ & $7.28 \pm 0.78$ & $7.03 \pm 0.81$ & $7.26 \pm 0.71$ \\
\hline Blend 8 & Whole wheat flour+Chickpea & $75+25$ & $7.56 \pm 0.88$ & $7.28 \pm 1.00$ & $7.32 \pm 0.86$ & $7.46 \pm 0.44$ & $7.32 \pm 0.96$ & $7.38 \pm 0.84$ \\
\hline Blend 9 & Whole wheat flour+Barley+Chickpea & $25+50+25$ & $7.36 \pm 1.10$ & $7.17 \pm 1.06$ & $7.11 \pm 1.26$ & $7.14 \pm 0.20$ & $7.11 \pm 1.06$ & $7.29 \pm 0.96$ \\
\hline Blend 10 & Whole wheat flour+Barley+Chickpea & $50+25+25$ & $7.61 \pm 0.84$ & $7.58 \pm 0.65$ & $7.22 \pm 0.93$ & $7.47 \pm 0.81$ & $7.28 \pm 1.30$ & $7.56 \pm 0.82$ \\
\hline Control & Whole wheat flour & 100 & $7.97 \pm 0.36$ & $7.97 \pm 0.43$ & $8.03 \pm 0.33$ & $8.01 \pm 0.32$ & $8.05 \pm 0.35$ & $8.03 \pm 0.25$ \\
\hline CD at 5\% & & & 0.24 & 0.25 & 0.27 & 0.26 & 0.26 & 0.22 \\
\hline
\end{tabular}

Values are presented as Mean \pm SD

Key to scores: 9= Like extremely, $8=$ Like very much, $7=$ Like moderately, $6=$ Like slightly, $5=$ Neither like or nor dislike, 4= Dislike slightly, 3= Dislike moderately, 2= Dislike very much, $1=$ Dislike extremely

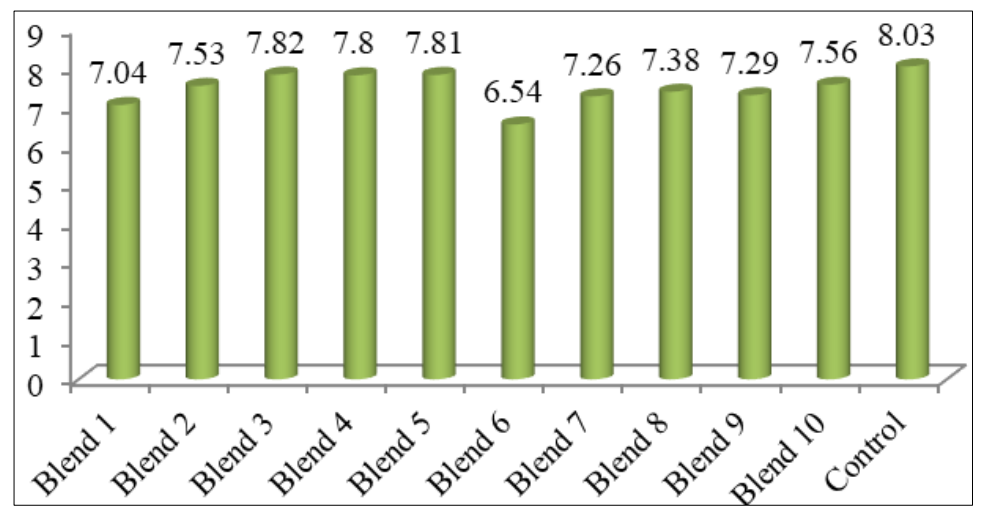

Fig 1: Overall acceptability scores of chapaties prepared from different blends $\sim 2541 \sim$ 
Proximate composition of most acceptable chapati sample The proximate composition of most accepted chapatti has been given in Table 3 .

\section{Chapati}

The chapaties prepared from blend 3 comprising of whole wheat flour and soy flour (75 and 25\%) and blend 5 comprising of whole wheat flour, barley flour and soy flour $(50,25$ and $25 \%)$ had higher overall acceptability, so were selected for proximate analysis. The comparison of the proximate principles of blends with the control (whole wheat flour) was made.

The results revealed that the moisture content of blend 3 and 5 had significantly $(p<0.05)$ lower moisture content i.e. 1.71 and $1.63 \mathrm{~g} / 100 \mathrm{~g}$, respectively as compared to the control
$(2.58 \mathrm{~g} / 100 \mathrm{~g})$ but no significant difference in moisture content was found between two blends (Table 3 ). The ash content was found to be significantly more in blend $3(2.40 \mathrm{~g} / 100 \mathrm{~g})$ and blend $5(2.55 \mathrm{~g} / 100 \mathrm{~g})$ when compared with the control $(1.4 \mathrm{~g} / 100 \mathrm{~g})$ but no significant difference in ash content was observed between the two blends. The high ash content of chapaties prepared from two blends was attributed to the supplementation of soy flour.

Similarly, the crude fibre content of the blend 3 and blend 5 was found to be significantly more i.e. 1.47 and $1.16 \mathrm{~g} / 100 \mathrm{~g}$, respectively when compared to the control $(0.79 \mathrm{~g} / 100 \mathrm{~g})$ but the difference between the two blends was found to be nonsignificant. Sharma (2009) ${ }^{[14]}$ observed that the test missi roti supplemented with $30 \%$ oats had $3 \%$ moisture, $0.9 \%$ ash, $16.9 \%$ crude protein, $3 \%$ fat and $5.4 \%$ crude fibre.
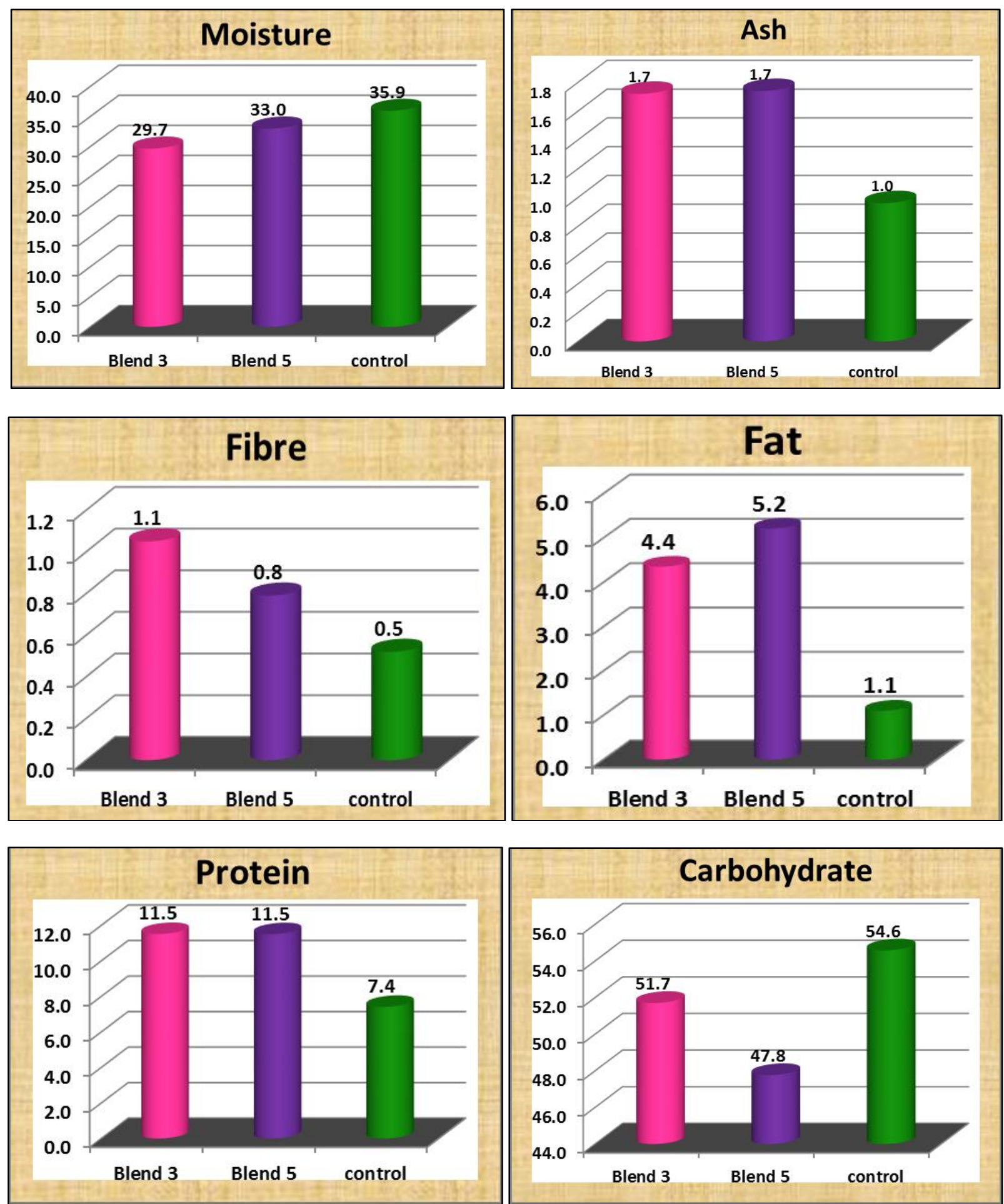


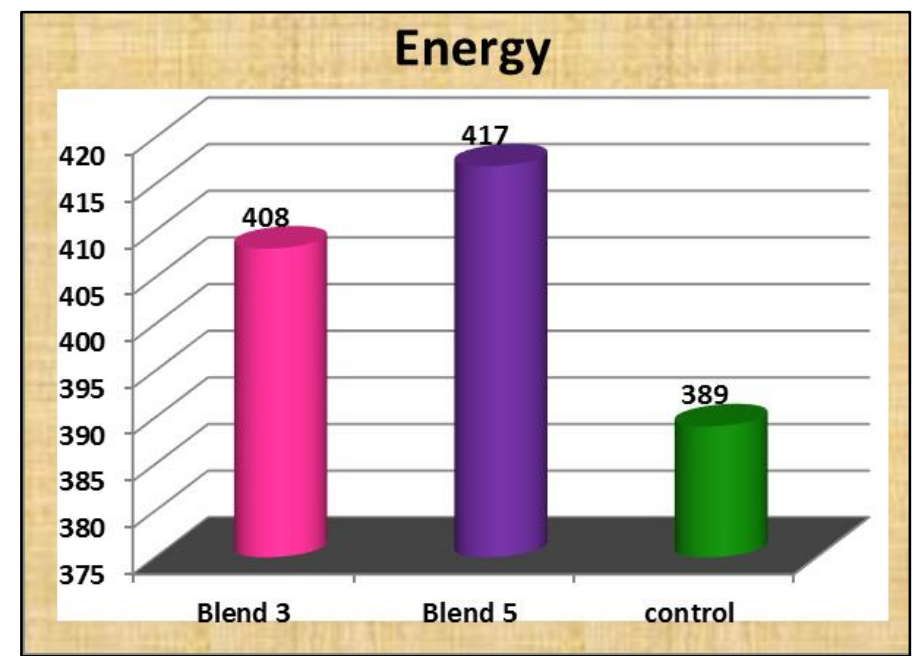

Fig 2: Proximate composition of selected blends of chapati (g/100g on fresh weight basis)

Blend 3: whole wheat flour, soy flour $(75+25)$, Blend 5: whole wheat flour, barley flour and soy flour $(50+25+25)$, Control: whole wheat flour

Table 3: Proximate composition of selected blends of chapati ( $\mathrm{g} / 100 \mathrm{~g}$ on dry weight basis)

\begin{tabular}{|c|c|c|c|c|c|c|c|c|c|}
\hline Blends & Flour combinations & Amount (g/100g) & Moisture & Total Ash & Crude Fibre & Crude Fat & Crude Protein & Carbohydrate Energy (kcal) \\
\hline Blend 3 & Whole wheat flour+Soybean & $75+25$ & $1.71 \pm 0.05$ & $2.4 \pm 0.06$ & $1.47 \pm 0.08$ & $6.08 \pm 0.25$ & $16.09 \pm 0.06$ & $72 \pm 0.12$ & 408 \\
\hline Blend 5 & Whole wheat flour + Barley + Soybean & $50+25+25$ & $1.63 \pm 0.13$ & $2.55 \pm 0.06$ & $1.16 \pm 0.20$ & $7.65 \pm 0.15$ & $16.88 \pm 0.16$ & $70 \pm 0.03$ & 417 \\
\hline Control & Whole wheat flour & 100 & $2.58 \pm 0.46$ & $1.45 \pm 0.09$ & $0.79 \pm 0.25$ & $1.66 \pm 0.00$ & $11.18 \pm 0.59$ & $82 \pm 0.29$ & 389 \\
\hline CD at 5\% & & & 0.82 & 0.21 & 0.57 & 0.50 & 1.05 & 0.55 \\
\hline
\end{tabular}

The fat content of blend 3 and blend 5 was found to be significantly more when compared to the control. The crude protein content of blend 3 and blend 5 was significantly ( $p<0.05$ ) more i.e. 16.09 and $16.88 \mathrm{~g} / 100 \mathrm{~g}$ as compared to the control. $(11.18 \mathrm{~g} / 100 \mathrm{~g})$ but no significant difference was found between two blends. The increase in fat and protein content was due to the incorporation of soy flour.

The available carbohydrates were 72.25 and $70.13 \mathrm{~g} / 100 \mathrm{~g}$ in blend 3 and 5 which were significantly lower than control $(82.43 \mathrm{~g} / 100 \mathrm{~g})$. The purpose to develop the products from these blends was to lower the carbohydrate content and ultimately the lower GI. The energy content of chapaties from blend 3 and blend 5 was 408 and $417 \mathrm{Kcal} / 100 \mathrm{~g}$.

On fresh weight basis, chapaties from blend 3 and 5 had $1.7 \%$ ash and $11.5 \%$ protein which were higher than the control. Besides this crude fibre, fat and energy was higher than the control recipe (Fig 2).

The findings concluded that supplementation of whole wheat flour with barley and soy flour significantly reduced carbohydrates and increased ash, fibre, fat and protein contents. Moreover these blends had higher acceptability, hence chapaties prepared from the blends of these flours will be suitable for the diabetics.

\section{Glycemic index of control and test chapati}

The glycemic index of control and test chapati is presented in Table 4.

The fasting blood glucose ranged from 67 to 112,83 to 88 and 75 to 83, respectively, in case of reference (glucose), control chapati (whole wheat flour) and test chapati (blend 5 comprising of wheat flour, barley flour and soy flour 50, 25 and 25\%)(Plate 1). The peak rise in blood glucose after half an hour, 1 hour, 1 hour 30 minutes and 2 hours ranged from 90 to 162,96 to142, 96 to127 and 83 to 119 in case of reference glucose (Fig 3). It ranged from 86 to101, 109 to115, 90 to119 and 85 to 103 in case of control chapati. Further in case of test chapati it ranged from 70 to 116,85 to 99,92 to
103 and 85 to $94 \mathrm{mg} / \mathrm{dl}$ respectively. It is evident from Table 4 and Fig. 3 that the blood glucose curve declined sharply in case of glucose (reference) where as a slow decline was observed in case of developed chapati. This could be due to the slow release of glucose. It could be due to the fact that the developed chapati (test chapati) is rich in complex carbohydrates and total dietary fiber which takes time for digestion and digests at a much slower rate than the free sugars. This would be beneficial for diabetics as satiety value for this chapati would be high. The glycemic index was found lower in test chapati (51.95) compared to glycemic index of control chapati (61.24) (Table 4).

Table 4: Glycemic index of control and test products

\begin{tabular}{|c|c|c|c|}
\hline Product & $\begin{array}{c}\text { Quantity administered } \\
\text { (grams) }\end{array}$ & GI & GI Category \\
\hline Chapati (control) & 92 & 61.24 & Moderate \\
\hline Chapati (test) & 104 & 51.95 & Low \\
\hline
\end{tabular}
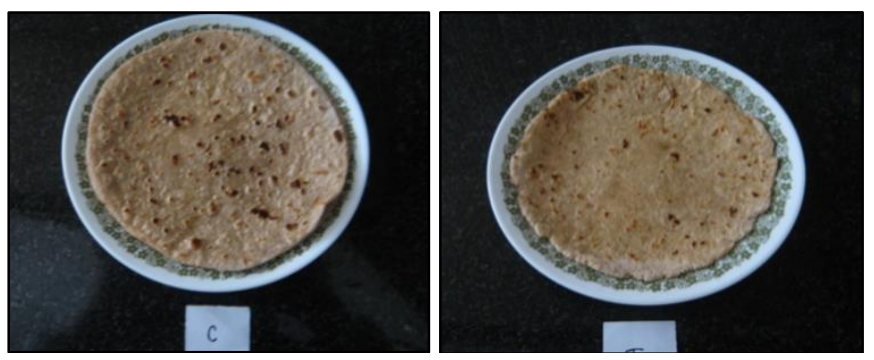

Control chapati: Whole wheat flour (100) Test chapati: Whole wheat flour, barley flour, Soy flour $(50+25+25)$

Plate 1: Chapati

The lowering of glycemic index in chapati can be attributed to the addition of legumes which contains $5-10 \%$ more amylose compared to cereal grains and this amylose is more resistant to digestion. With the incorporation of legumes, the protein content had increased and higher amount of proteins may 
physically encapsulate starch, preventing the enzyme access (Holm et al. 1989) ${ }^{[6]}$. Apart from this the crude fibre had also increased in test chapati. Dietary fibre inhibits starch digestibility by increasing the viscosity of intestinal contents and slow down the absorption of carbohydrates from the food (Wolever 1990) ${ }^{[16]}$.

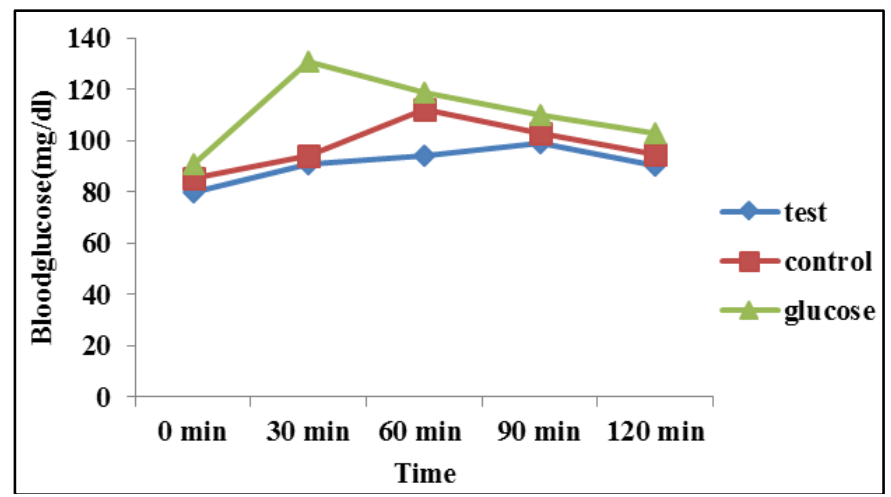

Fig 3: Mean blood glucose curves after consumption of glucose, control chapati and test chapati containing $50 \mathrm{~g}$ carbohydrates

Table 5: Glycemic load of developed products

\begin{tabular}{|c|c|c|c|c|}
\hline Product & GI & $\begin{array}{c}\text { Normal } \\
\text { serving size } \\
\text { (g) }\end{array}$ & $\begin{array}{c}\text { Available } \\
\text { carbohydrate } \\
\text { (g) }\end{array}$ & $\begin{array}{c}\text { Glycemic } \\
\text { load } \\
\text { (GL) }\end{array}$ \\
\hline Chapati (control) & 61.24 & 40 & 22 & 13.47 \\
\hline Chapati (test) & 51.95 & 40 & 19 & 9.87 \\
\hline
\end{tabular}

Table 5 displays that the mean GI and GL of the supplemented chapati was significantly lower as compared to the control chapati. Anything with GI value of 70 or more is a high GI food, moderate GI foods ranged from 56 to 69 and low GI foods have scores from 0 to 55 (Foster Powell et al. 2002) ${ }^{[4]}$. Whole wheat based chapati comprising of wheat flour, barley flour and soy flour $(50,25$ and $25 \%)$ with 51.95 glycemic index had $9.29 \%$ lower GI units when compared with control. It would have importance in north India where wheat is the staple food. Increase in protein and crude fiber and decrease in carbohydrates were responsible for lowering the glycemic value of the developed chapati. The developed chapati can be included in the regular diets of diabetics for the management of diabetes and to avoid any further complications.

\section{Conclusion}

The present study was conducted to develop the low GI chapati (Indian flat bread) and to evaluate the acceptability, nutritional composition and glycemic index of it. Oat, barley, soybean and chickpea flour were incorporated in the whole wheat flour to make chapati, by making 10 combinations of these flours. Ten samples of each product were prepared including a control. Maximum scores for colour and appearance (8.06) were observed in blend of wheat flour, barley flour and soy flour in the proportion of 50, 25 and $25 \%$. The results of proximate analysis revealed a significantly $(p \leq 0.05)$ higher fibre, protein and a significantly $(p \leq 0.05)$ lower carbohydrate content in the developed chapati. The Glycemic Index of chapati prepared from whole wheat flour, barley and soy flour $(50,25$ and $25 \%$ ), had significantly $(p \leq 0.05)$ lower GI (52) with $9.29 \%$ lower GI units. Thus it could be a healthy alternative for diabetic patients to manage the disease and to prevent further complications.

\section{Acknowledgements}

We thank the volunteers who participated in the GI testing study. The authors would like to thank the Head, department of Food and Nutrition for providing the research facilities. There are no conflicts of interest any with other organisation.

\section{References}

1. AOAC. Official methods of analysis. Association of official analytical chemist, Washington, DC, 2000.

2. Aston LM. Glycemic Index and metabolic disease risk. Proc Nutr Soc. 2006; 65:125-34.

3. Augustin LS, Franceshi S, Jenkins DJA. Glycemic index in chronic disease: a review. Eur J Clin Nutr. 2002; 56:1049-71.

4. Foster Powell K, Holt SHA, Brand Miller JC. International table of glycemic index and glycemic load values. Am J Clin Nutr. 2002; 76:5-56.

5. Gross LS, Li L, Ford ES, Liu S. Increased consumption of refined carbohydrates and the epidemic of type 2 diabetes in the United States: An Ecologic Assessment. Am J Clin Nutr. 2004; 79:774-79.

6. Holm J, Hagander B, Bjovk I, Eliasson A, Lundquist I. The effect of various thermal processes on the glycaemic response to whole grain wheat products in humans and rats. American I Nutr. 1989; 10:1531-33.

7. International Diabetes Federation. IDF Diabetes Atlas, 7th edition. Brussels, Belgium: International Diabetes Federation. 2015; 20157:55-63.

8. International Diabetes Federation. IDF Diabetes Atlas. 6th ed. Brussels, Belgium: International Diabetes Federation, 2013.

9. International Diabetes Federation. IDF Diabetes Atlas. 8th ed: International Diabetes Federation, 2017.

10. Jenkins DJA, Augustin LSA, Esfahani A, Kendall CWC. Glycemic index, dietary fiber, and human health: an historical perspective. Dietary fibre: an international perspective for harmonization of health benefits and energy values, 2008, 137-49.

11. Liu S, Willet WC, Stampfer MJ. A prospective study of dietary Glycemic load, carbohydrate intake and risk of coronary heart disease in US women. Am J Clin Nutr. 2000; 71:1455-61.

12. Salmeron J, Ascherio A, Rimm EB. Dietary Fiber, Glycemic load and risk of NIDDM in men. Diabetes Care. 1997a; 20:545-50.

13. Salmeron J, Manson JE, Stampfer MJ. Dietary fiber, glycemic load and risk of non-insulin dependent diabetes mellitus in women. JAMA, 1997b; 277:472-77.

14. Sharma V. Organoleptic and nutritional evaluation of fibre rich products from oats. M. Sc Thesis. Punjab Agricultural University, Ludhiana, Punjab, 2009.

15. Venn BJ, Green TJ. Glycemic index and glycemic load: measurement issues and their effect on diet-disease relationships. Eur J Clin Nutr. 2007; 1:S122-31.

16. Wolever TM. The glycemic index. World Rev Nutr Diet. 1990; 62:120-85.

17. Wolever TM, Jenkins DJA. The use of glycemic index in predicting the blood glucose response to mixed meals. Am J Clin Nutr. 1986; 43:163-172. 